\title{
Ectopic Cushing's syndrome and pulmonary carcinoid tumour identified by $\left[{ }^{111}\right.$ In-DTPA-D-Phe $\left.{ }^{1}\right]$ octreotide
}

\author{
J Matte, F Roufosse, P Rocmans, A Schoutens, D Jacobovitz, J Mockel
}

\begin{abstract}
Summary
The differential diagnosis and management of Cushing's syndrome remain difficult, particularly for ectopic adrenocorticotropin (ACTH) syndromes resulting from small bronchial carcinoids. We report the case of a 41-year-old man with ectopic ACTH-dependent Cushing's syndrome. Two computed tomography scans of the thorax were normal and magnetic resonance imaging of the chest showed a $6-\mathrm{mm}$ hyperintense $\mathbf{T} 1$-weighted area close to the left pulmonary hilus, interpreted as probably vascular by the radiologists. An [111 In-DTPA-D-Phe ${ }^{1}$ ]octreotide scintigraphy scan demonstrated a positive image for somatostatin receptors in exactly the same location and surgery confirmed the presence of a small ACTH-secreting carcinoid tumour in the upper left lung lobe which was resected. Surgery cured the hypercorticism of the patient. The differential diagnosis of Cushing's syndrome and the procedure for localisation of an ACTH source are discussed.
\end{abstract}

Keywords: Cushing's syndrome; carcinoid tumour; cortisol; adrenocorticotropin; octreotide scanning

Adrenocorticotropin (ACTH)-secreting tumours account for about $15-20 \%$ of cases of Cushing's syndrome. ${ }^{1}$ Small occult carcinoids frequently generate major diagnostic problems since up to $50 \%$ of them can mimic pituitary Cushing's disease with mild clinical signs, ACTH suppression by high-dose dexamethasone, and/or ACTH stimulation in response to metyrapone. $^{23}$ When a pituitary origin of ACTH has been reliably excluded by bilateral inferior petrosal sinus sampling with ovine corticotropin-releasing hormone (CRH) stimulation, ${ }^{4}$ detection of the tumour is sometimes impossible by computed tomography (CT) and magnetic resonance imaging (MRI) of the chest and abdomen, leading to palliative chemical or surgical adrenalectomy, the tumour being detected at follow-up sometimes years later at autopsy. ${ }^{1}$ The advent of somatostatin-receptor scintigraphy has been of great help in the identification of numerous neuroendocrine tumours, particularly ACTHsecreting medullary thyroid carcinoma, gastrinoma, and carcinoid. ${ }^{3}$ However, as noted by Doppman, ${ }^{5}$ a superior sensitivity of $\left[{ }^{111} \mathrm{In}\right.$ -
DTPA-D-Phe ${ }^{1}$ ]octreotide scanning compared to CT-MRI in the detection of bronchial carcinoids tumours has not been demonstrated by these series, since there were no negative $\mathrm{X}$-ray-MRI tumours with positive imaging exclusively by $\left[{ }^{111}\right.$ In-DTPA-D-Phe $\left.{ }^{1}\right]$ octreotide. The present case report illustrates such a situation and demonstrates that octreotide positivity of a tumour can be the main determinant of early curative surgery.

\section{Case report}

A 41-year-old previously healthy Caucasian man presented with a 18-month history of progressive weight gain $(5 \mathrm{~kg})$, fatigue, atypical left chest pain and impotence. He smoked 40 cigarettes daily for 24 years and drank beer moderately. He received $50 \mu \mathrm{g}$ of laevothyroxine od since the discovery of a euthyroid goiter four months before admission. There was no family history of endocrinopathy.

On physical examination, the patient had a normal weight (BMI: $21.4 \mathrm{~kg} / \mathrm{m}^{2}$ ) with a discrete moon facies and truncal (mostly supraclavicular) fat deposition, but marked amyotrophy of the extremities. His pulse was 64 beats $/ \mathrm{min}$ and blood pressure $160 / 90 \mathrm{mmHg}$. A discrete diffuse goiter was found in the neck. There were no purple striae. The skin and hair distribution were normal, as was the rest of the examination. Initial laboratory evaluation showed a normal erythrocyte sedimentation rate, serum calcium, phosphorus, magnesium, liver function tests, renal function and blood cell values. Fasting glucose was $4.1 \mathrm{mmol} / \mathrm{l}$ (normal range 3.9-6.2), sodium $145 \mathrm{mmol} / 1$ (135-145), potassium 3.2 $\mathrm{mmol} / \mathrm{l}$ (3.5-4.8), chloride $100 \mathrm{mmol} / \mathrm{l}$ (97109), and bicarbonate $32 \mathrm{mmol} / \mathrm{l}(22-29)$. Fasting serum cortisol was $690 \mathrm{nmol} / 1$ (193-690), ACTH $18 \mathrm{pmol} / \mathrm{l}$ (4-22), dehydroepiandosterone $6.4 \mu \mathrm{mol} / 1$ (5.4-9.5), aldosterone $166 \mathrm{pmol} / 1$ (139-749), plasma renin activity less than 0.18 ng/1/s. Fasting thyroid-stimulating hormone level was $0.08 \mathrm{mU} / \mathrm{l}(0.1-4)$, thyroxine 120 $\mathrm{nmol} / 1$ (72-157), triiodothyronine $1.3 \mathrm{nmol} / 1$ (0.59-2.07), growth hormone $0.7 \mu \mathrm{g} / 1(0-5)$, follicle-stimulating hormone $6.5 \mathrm{IU} / 1(2.0-7.5)$, luteinising hormone $2 \mathrm{IU} / 1$ (1.5-10), prolactin $8.5 \mu \mathrm{g} / \mathrm{l}(<10)$, testosterone $5.2 \mathrm{nmol} / 1(10.4$ 34.7), sex hormone binding globulin $5 \mathrm{ng} / \mathrm{ml}$ (2.9-14.5), calcitonin $<10 \mathrm{ng} / 1(0-15)$, carcinoembryonic antigen $2.2 \mathrm{ng} / \mathrm{ml}(0-5)$, cancer antigen $19.9<7.5 \mathrm{U} / \mathrm{ml}$. Free urinary cortisol varied between 1586 and $2792 \mathrm{nmol} /$ day 
(41-165), 17-hydroxycorticosteroids $89 \mu \mathrm{mol} /$ day (8-30), 5-hydroxyindole acetic acid (5HIAA) $13 \mu \mathrm{mol} /$ day $(10-41)$. Urinary dopamine, epinephrine, norepinephrine, metanephrine and normetanephrine were normal.

Under a standard low- and high-dose dexamethasone suppression test (Liddle test), serum cortisol decreased from $731 \mathrm{nmol} / 1$ at baseline to $552 \mathrm{nmol} / \mathrm{l}$ after dexamethasone 2 $\mathrm{mg} /$ day and to $207 \mathrm{nmol} / 1$ after dexamethasone $8 \mathrm{mg} /$ day. Urinary 17-hydroxycorticosteroids were reduced sequentially from $89 \mu \mathrm{mol} /$ day to $53 \mu \mathrm{mol} /$ day and thence to $21 \mu \mathrm{mol} /$ day. A corticotropin-releasing factor (CRF) test (100 $\mu \mathrm{g}$ intravenously) showed a $24 \%$ increase in ACTH (from 13 to $16 \mathrm{pmol} / \mathrm{l}$ ) and a $16 \%$ increase in serum cortisol (from 662 to 773 $\mathrm{nmol} / \mathrm{l})$. A short metyrapone test $(500 \mathrm{mg} / \mathrm{h}$ for six hours) raised ACTH to $583 \%$ of baseline (from 13 to $92 \mathrm{pmol} / \mathrm{l}$ ), serum 11-deoxycortisol to $125 \%$ of baseline (from 6.1 to $765 \mathrm{nmol} / \mathrm{l}$ ) and stimulated 17-hydroxycorticosteroid secretion by 2.75 (from 78 to $215 \mu \mathrm{mol} / \mathrm{d}$ ). These data demonstrated an ACTH-dependent nonsuppressible hypercorticism, unresponsive to CRF but potently stimulated by metyrapone. MRI of the hypothalamic and pituitary regions without and with gadolinium contrast was normal and bilateral inferior petrosal venous sinus sampling after CRF stimulation showed no ACTH concentration gradient between the inferior petrosal venous sinus samples and peripheral blood.

An abdominal CT scan was normal, as well as two CT scans of the chest (5-mm sections), bronchial arteriography, bronchoscopic examination and positron emission tomography of the thorax (methionine and fluorodeoxyglucose). MRI of the thorax showed a $6-\mathrm{mm}$ nodular lesion in the left upper pulmonary lobe close to the hilus which was interpreted as a venous component. An [ ${ }^{111}$ In-DTPA-DPhe ${ }^{1}$ ]octreotide planar scintigraphy scan revealed a small spot of octreotide uptake in the left lung supra-hilar region. A single octreotide administration (100 $\mu \mathrm{g}$ subcutaneously) was, however, not followed by any ACTH suppression (measured every $2 \mathrm{~h}$ for $16 \mathrm{~h}$ after administration of the drug).

CONFIRMATORY ${ }^{111}$ In-OCTREOTIDE SCINTIGRAPHY Scintigraphy was performed using intravenous injection of $8 \mathrm{mCi}(300 \mathrm{Mbq})$ of ${ }^{111} \mathrm{In}-\mathrm{DTPA}-$ D-Phe ${ }^{1}$ octreotide (Octreoscan, Mallinckrodt) followed by planar images of the head and trunk areas at 4 and 24 hours postinjection. An abnormal lung uptake in the left upper lobe was already present at 4 hours and was more precisely localised by a sequential tomographic examination (SPECT) of the thorax, first with $\left[{ }^{111}\right.$ In-DTPA-D-Phe $\left.{ }^{1}\right]$ octreotide and then, without displacing the patient, in vivo labelling of the red cells with $99 \mathrm{mTc}$ (Technescan ${ }^{\mathrm{R}}$ PYP, Mallinckrodt). The superposition of the different tomographic slices in the three planes allowed for the positioning of the tumour relative to the aortic arch and the left pulmonary artery. This functional localisation corresponding to the MRI scan was instrumental in convincing our surgeon to perform a thora-

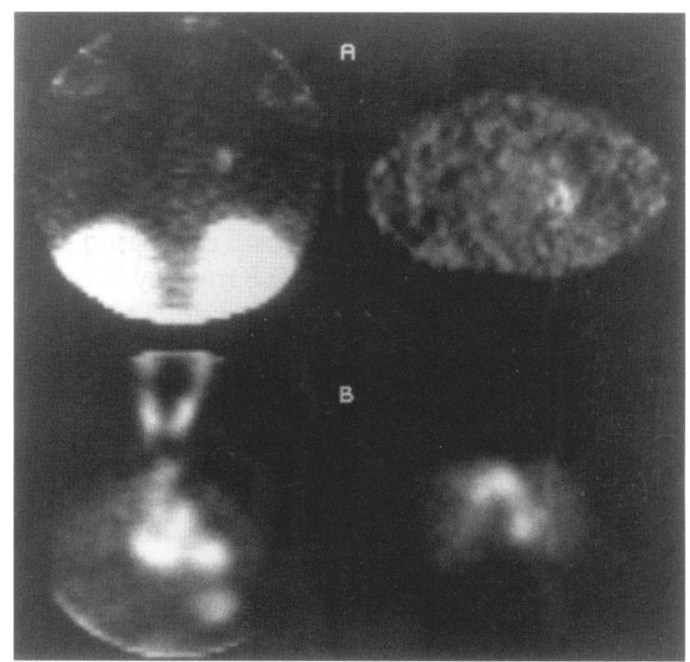

Figure Frontal (left side) and transverse (right side) reconstructed section of tomoscintigraphy. (A) ["1'In-DTPA-D-Phe'] octreotide: focal left pulmonary uptake; high activity in the abdomen. (B) $99 \mathrm{mTc}-$ labelled red cells: thyroid, heart cavities, pulmonary artery and aortic arch on the left; ascending and descending aorta on the right

cotomy with left upper lobe exploration (figure).

DIAGNOSTIC PROCEDURE

The patient underwent a left anterior thoracotomy. Lymph nodes were not enlarged and were normal on frozen sections. The left lung was macroscopically normal. By palpation the surgeon could localise a small nodule in the superior left lobe, close to the bronchus. A wedge resection confirmed a 5-mm large carcinoid tumour. A left upper lobectomy was performed. Macroscopic examination of the resected lobe disclosed no residual lesion and no lymph node dissemination (T1NOM0). Microscopically the final pathology demonstrated a localised neuroendocrine cell proliferation in the bronchial wall and a 5-mm limited nodule in the parenchyma. The tumour had a uniform cellular appearance and a tubular pattern. Immunohistochemically the cells expressed NSE, Leu 7Ag, chromogranin A and synaptophysin, confirming the diagnosis of a carcinoid tumour of the lung. Two months after surgery the patient was feeling well and on $25 \mathrm{mg}$ of cortisone acetate every two days, serum ACTH was $14 \mathrm{pg} / \mathrm{ml}$ and cortisoluria normal.

\section{Discussion}

This patient's disease clearly fulfilled the diagnosis of Cushing's syndrome, with massive urinary free cortisol excretion and almost no suppression of the hypothalamo-pituitary-adrenal axis after low-dose dexamethasone administration. The high level of ACTH ruled out an ACTH-independent disease. About $85 \%$ of patients with ACTH-dependent Cushing's syndrome have ACTH-secreting pituitary adenoma. Most of the remaining patients have ACTH-secreting non-pituitary tumours. ${ }^{1}$

No single endocrinological test affords complete discrimination between both types of 
Cushing's syndrome, and multiple testing has often to be performed to identify the ACTH source. ${ }^{6}$ High doses of glucocorticoids usually suppress ACTH and cortisol production in pituitary Cushing's syndrome but not in adrenal and ectopic ACTH secretion syndrome. Serum cortisol decreased significantly after dexamethasone $8 \mathrm{mg} /$ day in our patient but remained above the $5 \mu \mathrm{g} / \mathrm{dl}$ level, which is generally accepted as a good criterion of suppression. Pituitary ACTHsecreting adenomas are usually hypersensitive to $\mathrm{CRH}$, most of them showing an exaggerated ACTH response. In our case, CRH administration did not increase serum ACTH by more than $24 \%$ and serum cortisol by more than $16 \%$ from baseline, far less than the $50 \%$ and $20 \%$ increases for serum ACTH and cortisol, respectively, accepted as an exaggerated response. These two tests suggest a non-pituitary ACTH source. ACTH- secreting pituitary adenomas remain generally sensitive to the inhibitory effect of cortisol on the hypothalamic-pituitaryadrenal axis, while adrenal tumours and ectopic ACTH-secreting tumours are not. Under the action of metyrapone, most ACTH-secreting pituitary adenomas show an increase in 17hydroxycorticosteroid secretion of at least $200 \%$ of baseline and a 11-deoxycortisol raised over 10 $\mu \mathrm{g} / \mathrm{dl}^{6}{ }^{6}$ In our patient the response of 11 deoxycortisol fulfilled the criteria of a pituitary ACTH-secreting adenoma, but a recent review of the metyrapone test showed that at least 400fold increases of 11-deoxycortisol are necessary to exclude an ectopic ACTH source. ${ }^{6}$ Finally, inferior petrosal venous sinus sampling after $\mathrm{CRH}$ stimulation, known to show a sensitivity and specificity of almost $100 \%$ in the correct diagnosis of Cushing's disease, ${ }^{4}$ practically excluded the presence of a pituitary ACTHsecreting adenoma in our patient.

Routine clinical and radiological investigations, including CT of the abdomen and chest, failed to localise the tumoural source of the ACTH. Most occult tumours producing ACTH are small carcinoids located inside the thorax. ${ }^{1}$ Classical endocrine work-up in these tumours can be very misleading, up to $93 \%$ showing pituitary-like behaviour and only a few high urinary 5-HIAA excretion. ${ }^{1} \mathrm{MRI}$ has been recognised as being more sensitive than CT in detecting small pulmonary carcinoids arising in the close vicinity of the pulmonary hilus. ${ }^{8}$ In our patient, MRI of the chest showed a small area of increased $T_{1}$ intensity close to the left hilus, but

1 Limper AH, Carpenter PC, Scheithauer B, Staats BA. The Cushing syndrome induced by bronchial carcinoid tumors. Ann Intern Med 1992;117:209-14.

2 Pass HI, Doppman JL, Nieman L, et al. Management of the ectopic ACTH syndrome due to thoracic carcinoids. Ann Thorac Surg 1990;50:52-7.

3 de Herder WW, Krenning EP, Malchoff CD, et al. Somatostatin receptor scintigraphy: its value in tumor localization in patients with Cushing's syndrome caused by ectopic corticotropin or corticotropin-releasing hormone secretion Am F Med 1994;96:305-12.

4 Oldfield EH, Doppman JL, Nieman LK, et al. Petrosal sinus sampling with and without corticotropin-releasing hormone for the differential diagnosis of Cushing's syndrome. $N$ Eng f Med 1991;325:897-905.

5 Doppman JL. Somatostatin receptor scintigraphy and the ectopic ACTH syndrome: the solution or just another test? Am $\mathcal{F}$ Med 1994;96:303-4.

6 Avgerinos PC, Yanovski JA, Oldfield EH, Nieman LK, Cut the radiologist could not differentiate it from parahilar venous structures. Carcinoid tumours are of neuroendocrine origin, most of them express surface somatostatin receptors and can be localised with [ ${ }^{111}$ In-DTPA-D-Phe ${ }^{1}$ octreotide scintigraphy. ${ }^{3}$ This imaging technique showed a small clear-cut octreotide uptake close to the left pulmonary hilus, in the same location as the small hyperintense image of the MRI. The technique has a high sensitivity but cannot differentiate between neuroendocrine tumours and other pulmonary lesions like non-small-cell carcinomas, pulmonary metastases and even inflammatory lesions. Despite this positive imaging, the subcutaneous injection of $100 \mu \mathrm{g}$ octreotide had no effect on ACTH or cortisol plasma levels. In a recent series, a positive correlation was established between tumour visualization by $\left[{ }^{111}\right.$ In-DTPA-D-Phe $\left.{ }^{1}\right]$ octreotide and therapeutic response to the treatment, but much higher doses of the drug were used. ${ }^{3}$ It is noteworthy that there is no standardised test dose of octreotide allowing systematic prediction of a positive/negative response to a trial treatment. This is quite different from the situation observed in acromegaly, where a growth hormone reference value measured after a 100 $\mu \mathrm{g}$ dose of octreotide is predictive of the long-term results obtained with chronic treatment. In most studies that have evaluated the therapeutic success ${ }^{9}$ or failure ${ }^{10}$ of octreotide in ectopic ACTH-producing tumours, there was nocomparisonwith [ ${ }^{111}$ In-DTPA-D-Phe ${ }^{1}$ ]octreotide scintigraphy, but a $100 \mu \mathrm{g}$ test dose could be as efficient as a $1500 \mu \mathrm{g} / 24 \mathrm{~h}$ treatment. ${ }^{9}$

\section{Conclusion}

Management of Cushing's syndrome has always been a difficult problem. Since the generalisation of inferior petrosal sinus sampling for ACTH, with or without ovine CRH stimulation, the differentiation between pituitary ACTHdependent and non-pituitary ACTH-dependent Cushing's syndrome has been greatly improved. However, localisation of the ACTH source in documented ectopic Cushing's syndrome produced by occult tumours (particularly carcinoids) still remains very difficult. We show that $\left[{ }^{111}\right.$ In-DTPA-D-Phe ${ }^{1}$ octreotide scintigraphy can be sensitive and anatomically accurate in the localisation of lesions with negative or ambiguous radiological work-up and may allow early curative surgery.

ler GB Jr. The metyrapone and dexamethasone suppression tests for differential diagnosis of the adrenocorticotropindependent Cushing syndrome: a comparison. Ann Intern Med 1994;121:318-27.

7 Nieman LK, Chrousos GP, Oldfield EH, Avgerinos PC, Cutler GB, Loriaux DL. The ovine corticotropin-releasing hormone stimulation test and the dexamethasone test in the differential diagnosis of Cushing's syndrome. Ann Intern Med 1986;105:862-7.

8 Doppman JL, Pass HI, Nieman LK, et al. Detection of ACTH-producing bronchial carcinoid tumors: MR imaging vs CT. $A \not R R$ 1991;156:39-43.

9 Woodhouse NJ, Dagogo JS, Ahmed M, Judzewitsch R. Acute and long-term effects of octreotide in patients with ACTH-dependent Cushing's syndrome. Am $\mathcal{f}$ Med 1993 95:305-8.

10 Cheung NW, Boyages SC. Failure of somatostatin analogue to control Cushing's syndrome in two cases of ACTHproducing carcinoid tumours. Clin Endocrinol 1992;36:361-7. 